\title{
Magnetic modeling of the WeSt Iberian MARgin CONSTRAINED BY NEW GEOPHYSICAL DATA
}

\author{
Marta Neres ${ }^{1,2}$ \\ César Ranero ${ }^{3}$, Ingo Grevemeyer ${ }^{4}$, Irene Merino 3 , Valentì Sallarès ${ }^{3}$, Manel Prada ${ }^{3}$, \\ Alcinoe Calahorrano ${ }^{3}$, Alejandra Cameselle ${ }^{5}$
}

\author{
${ }_{1}^{1}$ Portuguese Institute for the Sea and Atmosphere, Marine Geology Division, Lisboa, Portugal \\ 2 Instituto Dom Luiz, Universidade Lisboa, Portugal \\ ${ }^{3}$ Institute of Marine Sciences-CSIC, Barcelona, Spain \\ ${ }^{4}$ GEOMAR, Germany \\ ${ }^{5}$ University of Vigo, Spain
}




\section{SOME HIGHLY DEBATED QUESTIONS ON WEST IBERIA MARGIN}

Nature of magnetic anomalies

Nature and structure of the lithosphere

Location and extent of Continent-Ocean transition

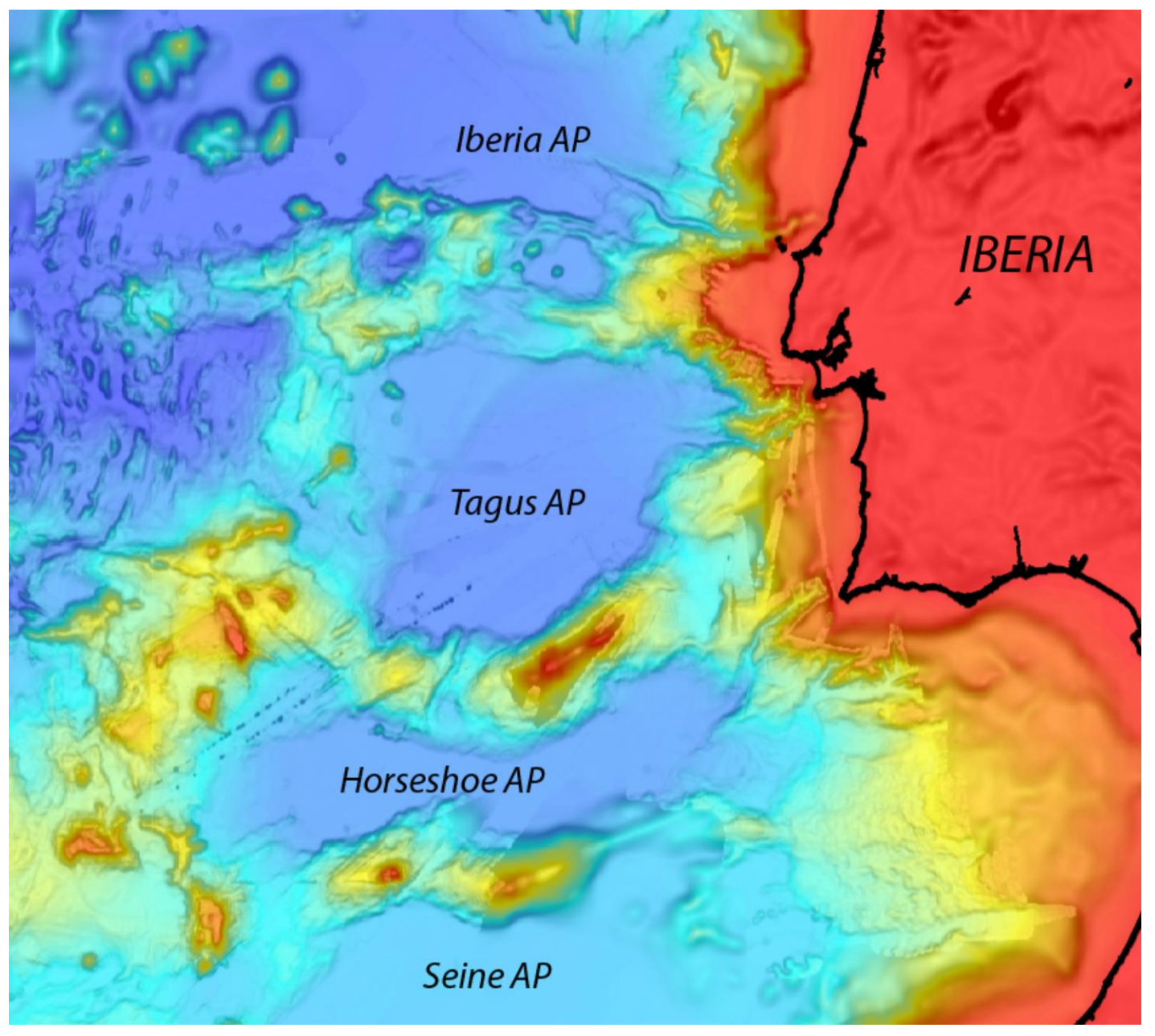

Links to Central Atlantic spreading

Role of magmatism in rifting, breakup and post-breakup processes 


\section{PROBLEMS WITH MAGNETIC DATA AND RECONSTRUCTIONS}

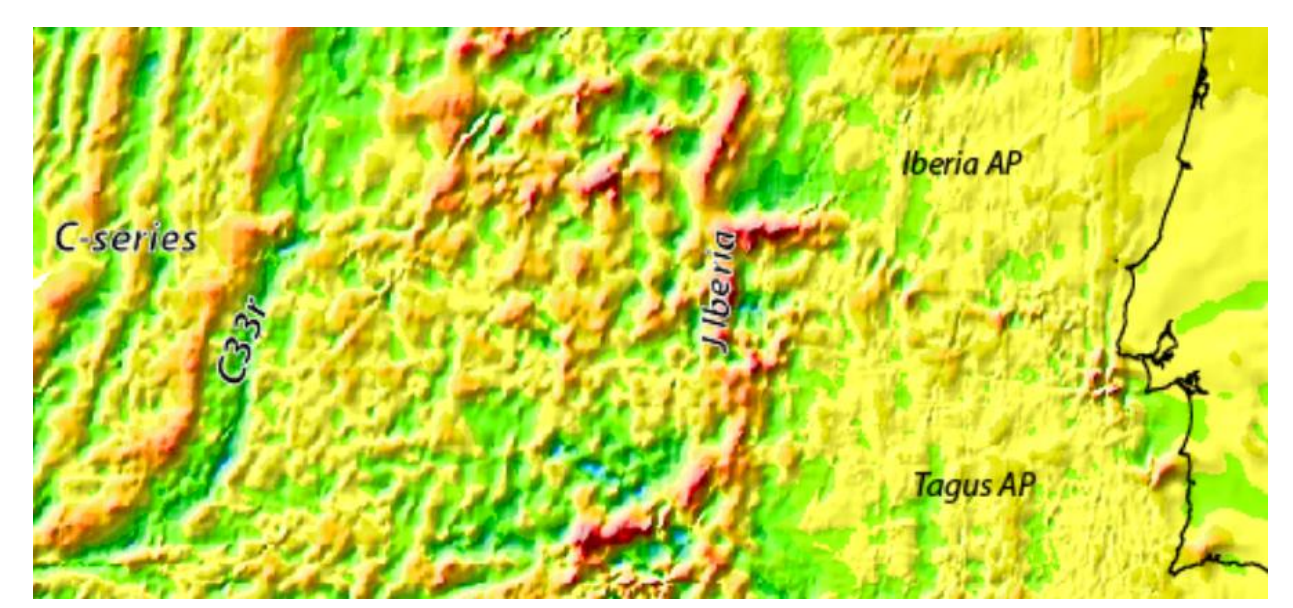

West Iberia Magnetic anomaly map

\section{Problems:}

The presence of M0 in West and North Iberia and even Newfoundland has been strongly questioned, and its identification is rather subjective.

Large uncertainties remain on the interpretation of the $\mathrm{J}$ anomaly. (Nirrengarten et al 2016; Bronner et al 2011)

The location and age of first oceanic crust is unknown.

Reconstructions have problems for lithospheric balance (formation, consumption) that are not sufficiently discussed.
Pre-C33r kinematic reconstructions are not consensual.

Importantly, M0 reconstructions depend on the criteria used for picking MO anomaly off-Iberia and off-Newfoundland.

Different reconstructions imply huge differences in the opening of Bay of Biscay and Pyrenean evolution.

(Olivet et al 1996; Sibuet et al 2004; Neres et al 2013; Vissers et al 2016; Barnett-Moore et al 2017)

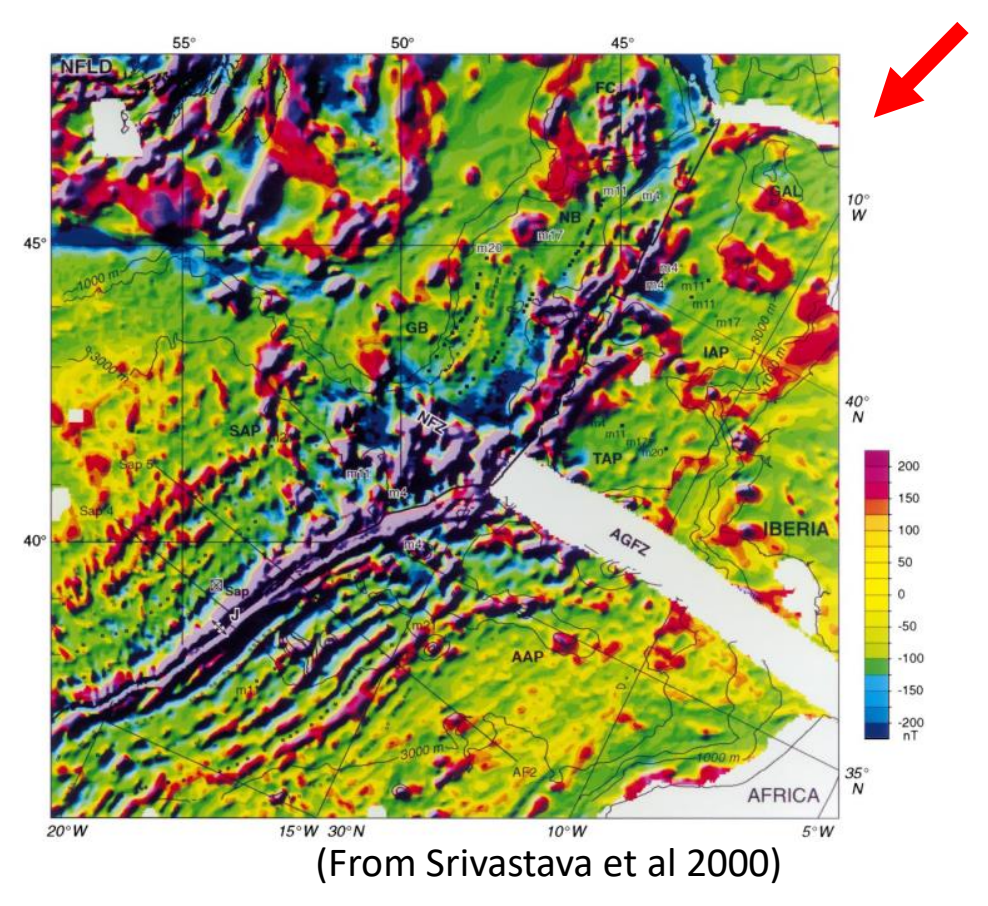

Alternative $\mathrm{MO}$ reconstructions based on distinct picking of anomalies
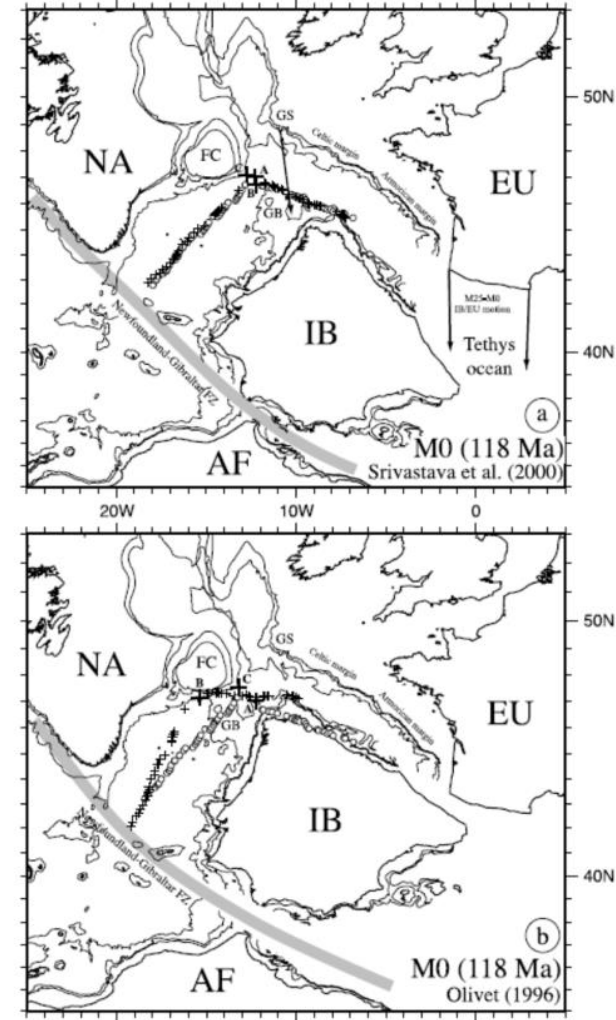

(From Sibuet et al 2004) 


\section{PROBLEMS WITH PALEOMAGNETIC DATA}

Pmag dataset used by Vissers et al 2016

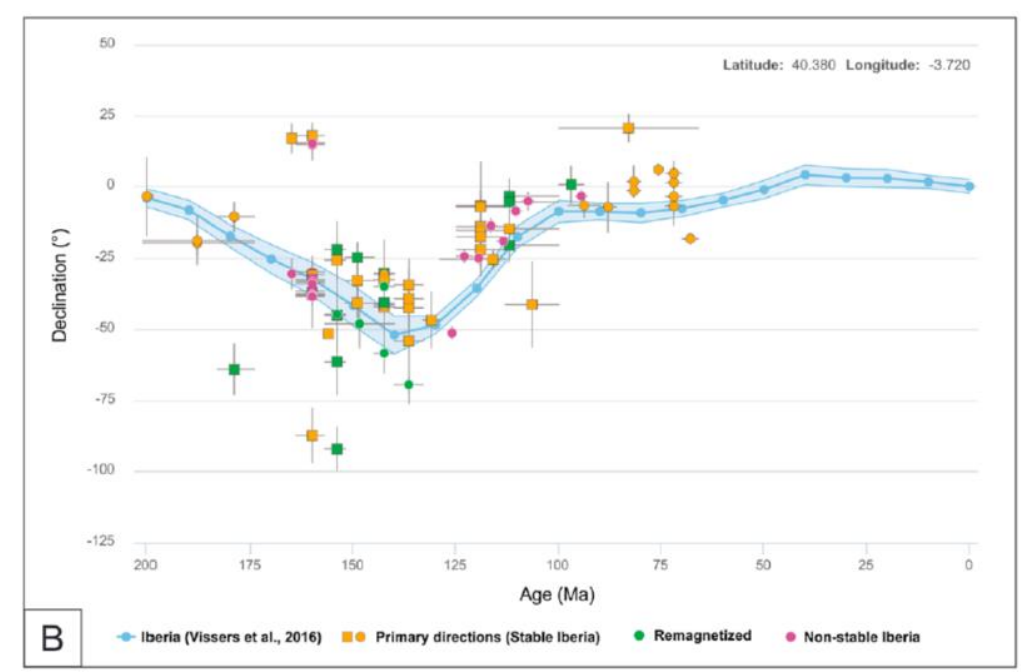

Reliable paleomagnetic data after quality-revision:

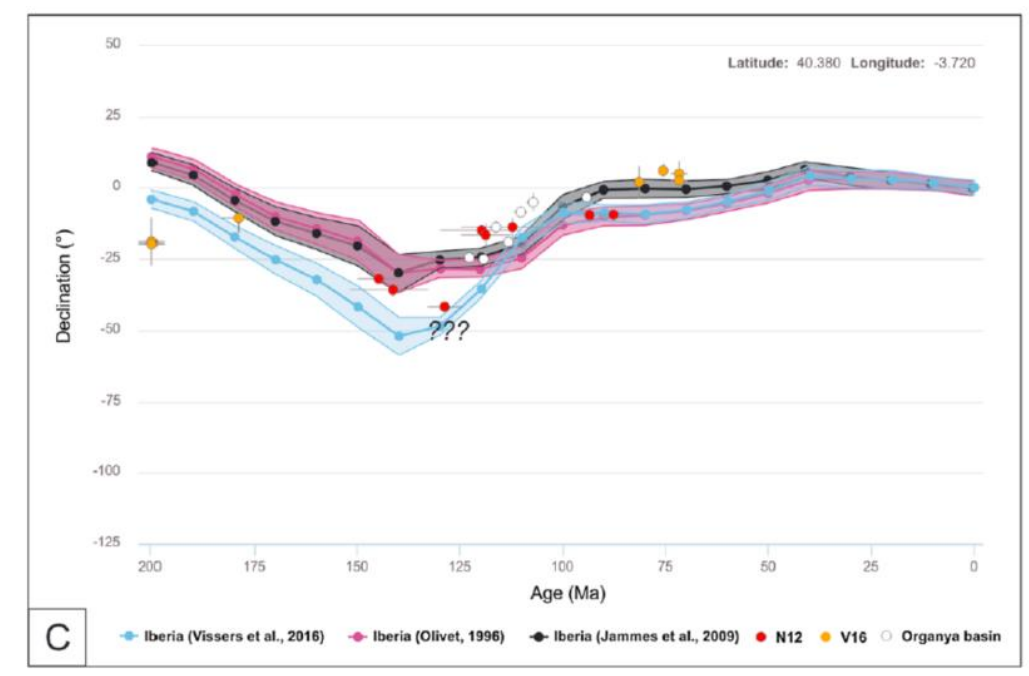

(From Barnett-Moore et al 2017)
One argument referred in the literature favoring the Srivastava et al's MO reconstruction and respective solution for Pyrenean orogeny is the argued agreement with paleomagnetic data (Gong et al, 2008; Vissers et al, 2016).

However, as shown by Neres et al, 2012; 2013 and by Barnett-Moore et al 2017, these are based on low-quality paleomagnetic data.

Kinematic solutions, Iberia paleomagnetic data and global APWP are still not conciliated. 


\section{NEW INSIGHT IS NEEDED}

Given the major implications that arise from these open questions, new approaches are needed towards a better understanding of Iberia structure and evolution.

Interpretation of magnetic anomalies, in particular J, off Iberia and off Newfoundland has lacked an integrative approach that may anchor the magnetic modeling on modern knowledge of the lithospheric structure.

Information on lithospheric structure has been constrained mostly by vintage low-resolution data

The few existent magnetic modeling does not support on lithospheric data

J anomaly modeling lacks realistic seismic-velocity-based assignment of layers' nature

Lack of high-quality data did not allow so far an integrative modeling and understanding of the magnetic anomaly and lithospheric structure data 


\section{NEW DATA BRING NEW INSIGHT}

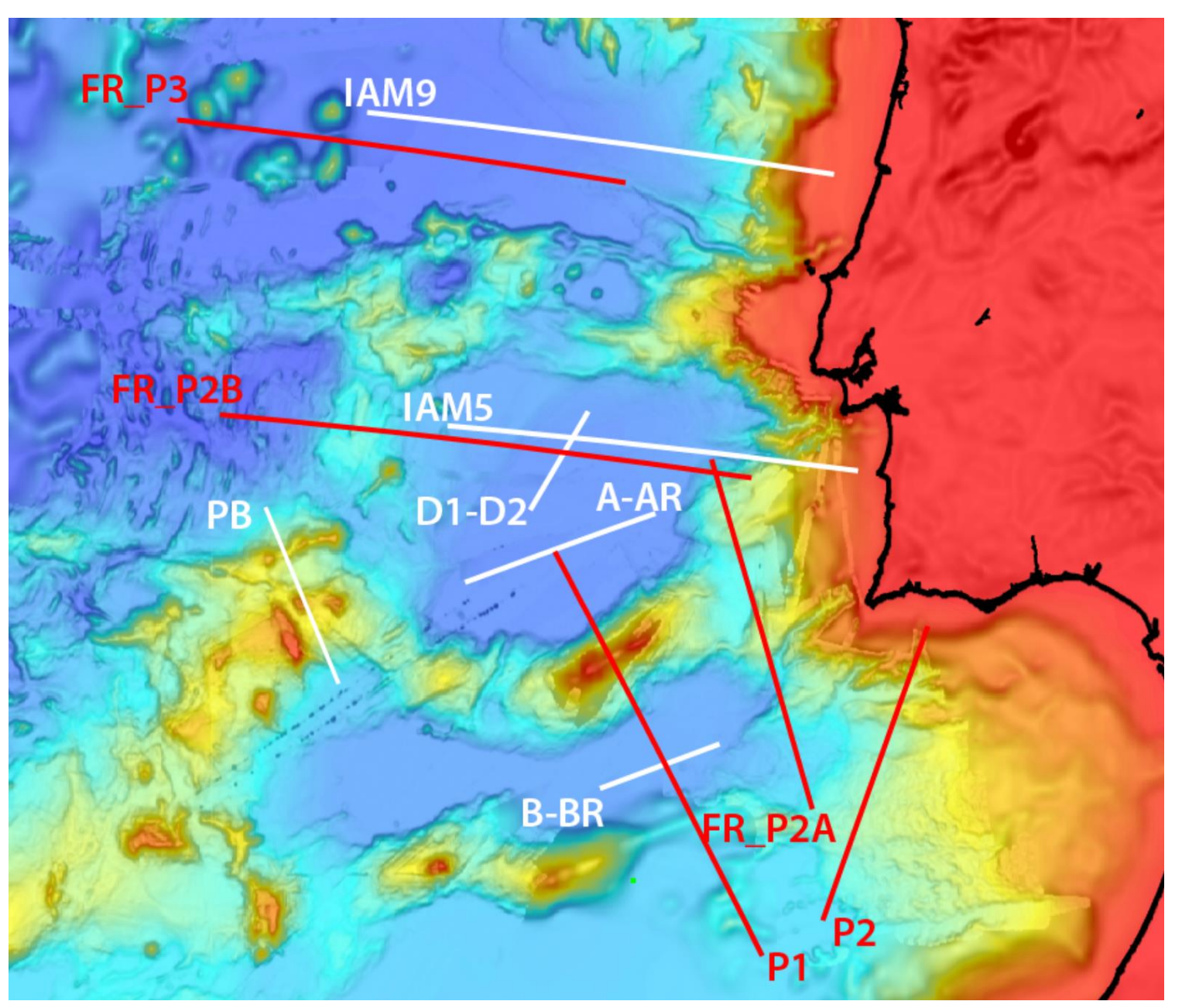

Recently, FRAME-2018 project collected new geophysical data across the Tagus and Iberia Abyssal Plains

FR_P2B and FR_P3 profiles cross the disputed lithospheric domains, including the J magnetic anomaly

FRAME acquired coincident magnetic, wide angle and multichannel seismic reflection data

\section{Wide-angle seismic data in West lberia:}

White lines: vintage, low-resolution

Red lines: recent high-quality data that provide high-resolution definition of the structure 


\section{WHAT IS OUR APPROACH?}

We use

recent high-quality magnetic data combined with high-quality wide angle data, multichannel seismic data and rock magnetism constraints

to achieve

realistic magnetic models that fit the observed data and are simultaneously consistent with the observed structure of the lithosphere,

which allow determining

the nature and geometry of the magnetic sources

and discussing

the processes implied in rifting and breakup, at both profile- and margin-scales. 


\section{REFERENCES}

Bronner, A., Sauter, D., Manatschal, G., Peron-Pinvidic, G. and Munschy, M., 2012. Reply to 'Problematic plate reconstruction'. Nat. Geosci., 5, $677-677$. doi:10.1038/ngeo1597.

Gong, Z., Langereis, C.G. And Mullender, T.A.T., 2008. The rotation of Iberia during the Aptian and the opening of the Bay of Biscay. Earth Planet. Sci. Lett., 273, 80-93. doi:10.1016/j.epsl.2008.06.016.

Neres, M., Font, E., Miranda, J.M., Camps, P., Terrinha, P. and Mirão, J., 2012. Reconciling Cretaceous paleomagnetic and marine magnetic data for Iberia: New Iberian paleomagnetic poles. J. Geophys. Res., 117, B06102. doi:10.1029/

2011JB009067.

Neres, M., Miranda, J.M. and Font, E., 2013. Testing Iberian kinematics at Jurassic-Cretaceous times. Tectonics, 32, 1312-1319. doi:10.1002/tect.20074.

Nirrengarten, Michael, et al. "Nature and origin of the J-magnetic anomaly offshore Iberia-Newfoundland: implications for plate reconstructions." Terra Nova 29.1 (2017): 20-28.

Olivet, J., 1996. La cinematique de la plaque Iberique. Bull. Centres Rech. Explor.-Prod. Elf-Aquitaine, 20, 131-195.

Sibuet, J.-C., Srivastava, S.P. And Spakman, W., 2004. Pyrenean orogeny and plate kinematics. J. Geophys. Res. Solid Earth, 109, B08104. doi: 10.1029/2003JB002514.

Srivastava, S.P., Sibuet, J.C., Cande, S., Roest, W.R. and Reid, I.D., 2000. Magnetic evidence for slow seafloor spreading during the formation of the Newfoundland and Iberian margins. Earth Planet. Sci. Lett., 182, 61-76.

Vissers, R.L.M., van Hinsbergen, D.J.J., van der Meer, D.G. and Spakman, W., 2016. Cretaceous slab break-off in the Pyrenees: Iberian plate kinematics in paleomagnetic and mantle reference frames. Gondwana Res., 34, 49-59, doi:

10.1016/j.gr.2016.03.006. 